\title{
From Economic to Political Analysis of Library Decision Making*
}

In general, the more critical the decision, the less useful a cost-benefit analysis is to library decision makers. Political analysis is required, and Easton's conceptual framework is presented to suggest the utility of political analysis. A list of normative issues is derived from raising descriptive questions about the politics of university libraries.

$\mathbf{I}_{\mathrm{N}}$ N 1969 THE M.I.T. Press published a new volume, Systematic Analysis of University Libraries: An Application of Cost-Benefit Analysis to the M.I.T. Libraries, which might have signaled the entrance of economic analysis into the area of library decision making. As coauthor of the book, I anxiously awaited the reviews I hoped would follow. ${ }^{1}$ To date all reviews missed what I regard as the major point of the book: Although helpful, an economic analysis of a university (or public) library is insufficient because libraries operate as political systems and thus improving libraries requires political analysis.

The purpose of this paper is not only to argue that political analysis of university and public libraries should be undertaken in conjunction with economic analyses but also to apply a specific theoretical framework and concept to university and public libraries. The improvement of libraries requires an expansion of analysis beyond technical discussions of procedural changes and per item costs to the broader utilization of social science theory and research.

In the past two decades both econo-

Jeffrey A. Raffel is with the Division of Urban Affairs, University of Delaware, Newark. mists and political scientists have expanded their field of inquiry. Economists have become crucial figures in the analysis of governmental policy, especially in the measurement and analysis of governmental effectiveness through the methodology of cost-benefit analysis. ${ }^{2}$ Political scientists have at the same time shifted their focus toward nongovernmental institutions, with some analyzing what were once thought to be nonpolitical governmental institutions (e.g., schools) and others, nongovernments (e.g., private governments). As Mancur Olson has recently observed, the social science disciplines differ by their approaches and theoretical frameworks rather than by their subject matter. ${ }^{3}$ Thus libraries, be they primarily publicly or privately operated, are fair game for the frameworks of political scientists and economists.

Each discipline includes an array of theoretical frameworks. The overall ap-

'My frequent co-author, Robert Shishko, has tried to impart the essence of cost-benefit analyses to his audience by telling them about an economist who, when asked if he liked sex, replied immediately, "What are the alternatives?" I thank Bob Shishko for helping me to learn enough about economic analysis to criticize it, and I thank David Schulz and Daniel Rich for their insightful comments on earlier drafts of this paper. 
proach of systems analysis stands out within each discipline as a fruitful way to improve libraries, specifically costbenefit analysis in economics and Eastonian systems analysis in political science.

\section{Economic ANALYsis}

\section{Brief Description}

"Basically, economic analysis is the study of choice: the allocation of scarce resources among alternative uses, and the distribution of outputs among alternative uses-that is, the classic questions of what and how much to produce, and who gets what products." 4 Cost-benefit analysis is a subfield of economic analysis: a specific application of economic analysis to nonmarket activity. We have defined cost-benefit analysis as the analytical examination of the costs and benefits of alternatives designed to meet specified objectives under various contingencies or states of the world. ${ }^{5}$ Some differentiate cost-benefit analysis from cost-effectiveness analysis; the former referring to long-range financial effects (e.g., increased dollar income) and the latter to short-range measured output in nonfinancial terms (e.g., number of books circulated). ${ }^{6}$ Although systems analysis has been used to refer to cost-benefit analyses, because its use is much more widespread, having application in areas from computer technology to political analysis, we define systems analysis as the study of systems or complexes or organized and interrelated parts, in terms of inputs, outputs, and internal functioning. ${ }^{7}$

Our definition of cost-benefit analysis has already included most of the elements of the basic analytical framework: costs, benefits, alternatives, and contingencies. What then is cost-benefit analysis? It is a way of looking at the world. Usually one starts from a set of objectives that a decision maker has in mind. The analyst finds measures of the extent to which the objectives may be met. For example, if an objective of a library were to provide reading material to library users, then one measure of meeting this objective would be annual book circulation. One then examines the alternatives for fulfilling each objective.

By constructing models (e.g., formulas, computer simulations), the analyst relates each alternative to its corresponding costs and benefits (i.e., the degree to which objectives are met). The model is used across several contingencies or states of the world. Given the costs and benefits associated with each alternative in each contingency, a criterion or measure of preferredness (e.g., maximizing profits) is selected and the "best" alternative is chosen.

Figure 1 illustrates the cost-benefit procedure. Note that the method is actually circular-objectives are revised in light of feasibility and costs, new alternatives are created, models are refined, and the decision process is continuously in motion.

\section{Brief Critique}

The elements of the cost-benefit analysis model serve as the basis for a brief critique of the method. Attempts to define library objectives can lead to clarifications of purpose, yet they often result in futile searches for well-hidden goals obscuring the true clients of the library. ${ }^{8}$ While efforts to generate alternatives to perform library services more efficiently and effectively are made, the question of the practicality and feasibility of radically different ideas weights the ultimate analysis against innovative options. Relating costs to alternatives becomes the key task, and numbers generated through cost modeling become the foci of economy drives. Benefit modeling, however, is weakest when the alternatives are most innovative, e.g., public library programs based 


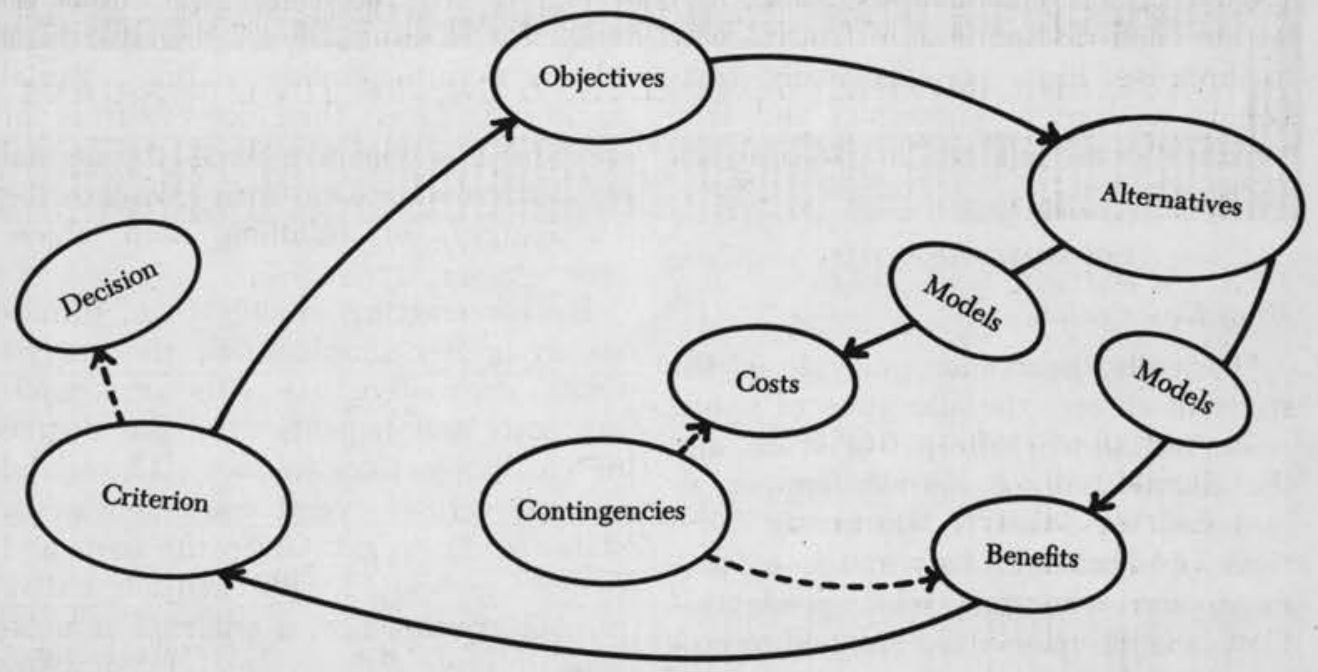

Fig. 1

The Basic Cost-Benefit Framework

on distributing paperback books for disadvantaged patrons, university libraries handing out free copies of required articles to students. ${ }^{9}$ Because the contingencies studied most are those thought to affect costs, not benefits, inflation of prices is emphasized over inflation of goals in serving users.

Each of these difficulties is related to the political context in which the economic study is conceived, implemented, and received. The basic political problem with economic analysis transcends operational and day-to-day difficulties and political intrigue. The basic political problem centers on political conflict inherent in all our institutions, including libraries. It is this conflict that is inappropriately dealt with or ignored in economic analysiș.

\section{The Political Problem with Economic Analysis: An Example}

Near the end of the data collection stage, the economic systems analysis of the Massachusetts Institute of Technology (M.I.T.) libraries yielded a list of twenty library alternatives with associated costs and benefits. ${ }^{10}$
At this stage in the analysis several points were evident:

1. Several alternatives were not worth considering. Alternatives offering fewer benefits at a higher cost than comparable alternatives were discarded. For example, storing books off campus rather than on campus saved no money and resulted in losses of benefits to library users.

2. Many conclusions with major policy implications were already warranted. For example, inexpensive storage appeared to offer little financial savings at a fairly high cost in benefits to a majority of the M.I.T. community.

3. Although alternatives could be described in terms of costs and benefits with respect to the two major library objectives, more information was required to select and recommend a subset of alternatives. For example, should the cost of reproducing copies of library materials be reduced or should many course-required articles be distributed free of charge? Should either 
be done with or without a decentralization of library space?11

It is at this point that cost-benefit analysis (and economic analysis) comes to a grinding halt. Cost-benefit analysis assumes that the objectives, even if unclear at the beginning of the analysis, can be specified at some point to the satisfaction of the decision maker. Costbenefit analysts recognize that multiple objectives may exist and suggest that the tradeoffs, the extent to which meeting one objective leads to a failure to meet other objectives, be specified and clearly displayed. But did our analysis indicate objectives that could be agreed upon?

We decided to present the data on alternatives derived from our analysis to the individual members of the university community, thus to allow each to act as if he or she were the ultimate decision maker. ${ }^{12}$ Because it would have been too costly to reach all members of the community, we drew a random sample of undergraduate students, graduate students, and faculty and research staff and presented them with twenty alternative changes, with a brief description of costs and relevant benefit considerations, for the M.I.T. libraries. Respondents were given budgets of $\$ 0, \$ 100,000$, and $\$ 200,000$ to spend for changes in the libraries.

The analysis of the survey clearly indicates that different subgroups of the M.I.T. community either had different objectives in mind or viewed different means as being best for meeting common objectives:

The general conclusion is that the three major campus groups differ in the systems they would like the library to adopt. Undergraduates seek to expand and centralize the reserve collection by cutting research services. Graduate students add lower Xerox prices and increased access to this list of desired systems and would prefer to cut seating rather than cataloging. The faculty are the most willing to alter book storage and cataloging and relatively less desirous of a centralized reserve system....

The less a respondent reported using the libraries the more likely he was to select saving money on book storage and seating and to spend it on lower Xerox rates, departmental libraries, and an all-Xerox reserve system. Low users thus tend to be outside-use oriented. The high users prefer expanding seating, acquisitions, reference, and access to other collections. The high users thus are research oriented. We have concluded that the library has traditionally served one clientele, the research oriented. There now appears to be, however, a second clientele, who spend few hours in the library and seek not the space but the materials in its collection. We believe, with as yet no proof, that many of those oriented to outside use prefer to work outside the library but are forced, primarily by the reserve system, to work in the library. We hypothesize that these users (and many other potential users) could be served by a library emphasizing distribution as well as in-house facilities and services. ${ }^{13}$

The M.I.T. analysis indicates that the alternatives faced by the M.I.T. library and university administrators involved major choices among various subgroups on campus. Furthermore, the analysis strongly suggests that decisions now favor faculty far more than students.

The political problem with economic analysis is that there is no economic way to resolve differences among alternatives meeting different objectives held by different subgroups; where political conflict exists a political solution must be found. ${ }^{14}$ This is not news to most economists. What library decision makers require is help in resolving these political conflicts. Presumably political analysis can help.

\section{Political Analysis}

Political scientists would not agree on the nature of analysis necessary to deal 
with such political conflict. Some would argue that an analysis should begin with a positivist or descriptive analysis of libraries with a focus on who decides and by what process. Others would argue that an explicitly normative or value based analysis, with a major focus on issues of equity and responsiveness, is required. Because neither of these approaches has been applied to libraries, a first step falling between the normative and positive poles of political systems analysis has been chosen here. Below, David Easton's descriptive framework is used to raise the normative questions which library decision makers should be addressing. ${ }^{15}$

Easton defines politics as the authoritative allocation of values for a society. In the past, many governmental institutions, perhaps education is the best example, have been viewed as being outside of the realm of politics. In 1969, in an introduction to a reader on the politics of education, the editor stated that "The idea that politics and public education are intimately related was practically unthinkable as recently as a decade ago. ... . At the very least, any governmental process involving authoritative decisions on matters of public relevance is of a political nature."16 Thus an entire literature dealing with the politics of education has developed. ${ }^{17}$ Certainly it would not be inappropriate to raise issues concerning the politics of public libraries and libraries at public universities.

Studying the politics of university libraries derives from another expansion of political analysis to the area of private government. ${ }^{18}$ Public governments have been defined as "those general as well as special-purpose associations and agencies either to which all inhabitants of a given locality are subject or of which all citizens are members"; and private governments are "those limitedpurpose associations or organizations, usually voluntary in membership, which exist both alongside and subordinate to public governments."19 Examples of private governments are corporations, trade unions, professional associations, and universities. Indeed, the public versus private distinction has become increasingly blurred, especially as applied to universities, within the past decade. ${ }^{20}$ The basic questions one asks about private governments are political: Are (and can) private governments (be) democratic?21 Related questions include: Who gets what, when, and how? 22

Although many alternative models of the political process exist, I believe that Easton's framework provides a useful analytical scheme for beginning a political analysis of libraries. ${ }^{23}$

\section{Easton's Framework for Political Analysis}

Easton's model (see Figure 2) is simple in its conception but complex in its full description. Dye describes the theoretical framework succinctly:

One way to conceive of public policy is to think of it as a response of a political system to forces brought to bear upon it from the environment. Forces generated in the environment which affect the political system are viewed as inputs. The environment is any condition or circumstance defined as external to the boundaries of the political system. The political system is that group of interrelated structures and processes which functions authoritatively to allocate values for a society. Outputs of the political system are authoritative value allocations of the system, and these allocations constitute public policy.

Systems theory portrays public policy as an output of the political system. The concept of "system" implies an identifiable set of institutions and activities in society that function to transform demands into authoritative decisions requiring the support of society. The concept of "systems" also 


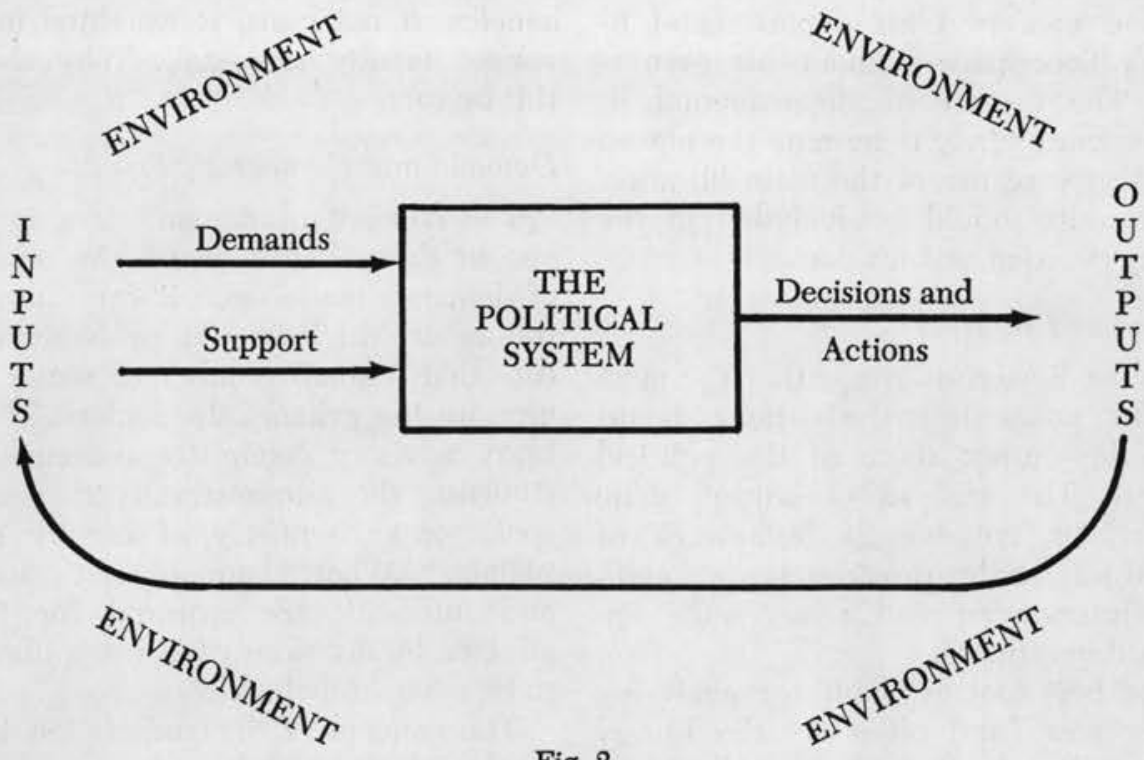

Fig. 2

The Systems Model

implies that elements of the system are interrelated, that the system can respond to forces in its environment, and that it will do so in order to preserve itself. Inputs are received into the political system in the form of both demands and support. Demands occur when individuals or groups, in response to real or perceived environmental conditions, act to affect public policy. Support is rendered when individuals or groups accept the outcome of elections, obey the laws, pay their taxes, and generally conform to policy decisions. Any system absorbs a variety of demands, some of which conflict with each other. In order to transform these demands into outputs (public policies), it must arrange settlements and enforce these settlements upon the parties concerned. It is recognized that outputs (public policies) may have a modifying effect on the environment and the demands arising from it, and may also have an effect upon the character of the political system. The system preserves itself by: (1) producing reasonably satisfying outputs, (2) relying upon deeply rooted attachments to the system itself, and (3) using, or threatening to use force. ${ }^{24}$

\section{Political ANalysis AND UNIVERSITY LIBRARIES}

\section{System Boundaries and Legitimacy}

The first question that arises is whether we can determine the boundaries of a political system. Throughout the M.I.T. library study we felt too constrained by the definition of the system we were studying, "the M.I.T. libraries." The use and evaluation of a university library are not independent of the book stores within (and without) the university. To declare one a legitimate item for analysis and the other as outside of the area of analysis may be to miss the dynamics of the situation. It was surprising to discover that a high-level, library acquisitions department staff member had not only made no effort to buy books from the Harvard Coop but also had never even been to this store, one of the world's largest bookstores. We were surprised to receive veiled threats by a department chairman after 
we had measured his departmental library's floor-space without his permission. The quality of departmental libraries must surely determine the nature and degree of use of the main libraries. What units should be included in the library decision maker's domain?

\section{Output and Benefits}

Unlike Easton, it seems that the most fruitful political analysis must begin with the output stage of the political process. The analysis of output, done within the cost-benefit framework of the M.I.T. study, provides some significant information and raises some important questions.

The best tool available for analyzing policy was (and often is) the library budget. But budgets are usually input based (e.g., cost of books purchased, cost of personnel salaries) rather than output or policy derived (e.g., cost of providing student services for coursework). Perhaps even more interesting, the M.I.T. library budget, divided into parts among discipline-related libraries, was considered confidential. To paraphrase one library administrator, "If the social scientists knew what we were spending on the physical science library, they'd start asking for more funds."

A program budget analysis of the M.I.T. library seems to show quite clearly who benefits from the current decision-making system. Only 23 percent of the total budget is used for providing required reading and facilities for studying, i.e., less than a quarter of the budget is devoted to nonresearch, courserelated student services. Of course, this overstates the antistudent bias, for undergraduate and particularly graduate students devote much effort to research both inside and outside of courses.

As noted in the discussion of the cost-benefit analysis of the M.I.T. libraries, the survey analysis challenges the myth of a unitary community. ${ }^{25}$ In fact it suggests that the allocation of benefits, if not costs, is weighted in favor of faculty and staff. Why should this be so?

\section{Demand and Democratic Process}

The concept of demand is a crucial one in Easton's framework. An analysis of demands made upon library administrators at M.I.T. would probably indicate that a small number of senior faculty are the primary demanders. The library advisory committee contained no students; the administrators themselves spoke almost entirely of faculty complaints. ${ }^{26}$ What channels, both formal and informal, are required for those affected by decisions concerning libraries to be adequately heard?

The concept of demands is too limited for the political analysis of quasipublic institutions like university libraries. Few preferences, defined as desired states of affairs, even reach the level of demands. Easton concentrates on the reasons for the weeding of demands and the attrition of preferences in the input stage of the political process. We should ask, as does Easton, what institutions exist to filter and channel demands to library decision makers? How successful are different kinds of people within the university community in making their demands heard? To what extend should access be equalized?

The mobilization of bias should also be considered crucial by library analysts. Several political scientists have criticized their discipline for the substantive conclusion that American institutions are open and responsive to minority groups. ${ }^{27}$ They argue that this optimistic substantive conclusion derives in part from a methodological problem, analyzing only decisions made by public bodies. Backrach and Baratz ask, "Can the researcher overlook the chance that some person or association could limit decision-making to relatively noncontroversial matters, by influencing community values and political procedures and 
rituals?"28 By limiting political analysis to overt decisions, the role that elites play in mobilizing bias, i.e., in defining the nature and states of the political game, is overlooked.

The mobilization of bias plays a critical role in library policy. One of our early suggestions at M.I.T. was that the price of reproducing pages of library materials within M.I.T.'s libraries should be reduced. Although the price was later decreased, the action was based upon an agreement that decreasing the price would ultimately increase revenue (i.e., elastic demand) and the system would remain self-supporting. But why should the dissemination of information by copying be self-supporting, and who is disadvantaged by this decision rule? Whereas many faculty have research grants, departmental resources, and relatively high incomes, students are at a relative disadvantage in the marketplace. Libraries do not break even on providing books. Should they break even on copying materials for dissemination?

One economist has made an argument that could have been based on the mobilization of bias concept:

\begin{abstract}
Or why do not librarians diminish their stock of hard-cover books and acquire in their stead substantial inventories of paperbacks which they would then give away free? We are inclined to reply, "Why, that would be crazy: our budget would soon be exhausted." And yet that is exactly what librarians are doing now except instead of giving books away free they are giving staff services away free. ${ }^{29}$
\end{abstract}

Keller calls for implicit (or explicit) pricing of library services. ${ }^{30}$

Easton's framework, indeed all political frameworks, should include a basic economic concept of exit. Hirschman argues that one mechanism of voicing disapproval within the political as well as economic sector is exit, e.g., leaving the organization or not consuming the product. ${ }^{31}$ To what extent do po- tential library users seek other sources of information because of library ineffectiveness? To what extent do some groups lack an effective means of influencing library decision makers by their inability to exit?

The larger question that each of these points concerning demand raises is the appropriateness of democratic norms for library decision making. Should libraries be run more democratically than they now are?

\section{Decision Making and Selecting Decision Makers}

The analysis of decisions and decision makers is a crucial aspect of Easton's framework. The analysis of library decision making must reach beyond the traditional organizational bounds of the exercise of rationality. Lakoff has expressed the criticisms of traditional organizational analysis as follows:

The study of organizational decisionmaking studiously avoids asking the kind of questions that would render the study of decision-making genuinely political. It does not ask what constituencies are involved, or how the legislative is related to the executive, or how the authority of the decisionmaker is made accountable to those he represents. It does not ask whether the system is constitutional or just, legitimate or illegitimate. Instead the study of decision-making in organizations is confined to the question of whether and to what extent the functions of management are exercised rationally. The stress, in other words, is clearly on administration rather than government, on the integrative function of social organization, on improving the efficiency of the decision-maker. There is practically no attention paid to the question of whether people who are members of the organization or who are served by it have or ought to have control over it, whether they have any right (a term which would probably be considered altogether un- 
scientific by students of organization) to be consulted in the decision-making process or indeed to decide what form the process will take. ${ }^{32}$

In this conventional sense, the study of organizations, despite its focus on decision making, has been quite apolitical.

Dye's identification of barriers limiting rational decision making, in many ways analogous to criticisms of the use of cost-benefit analysis in libraries, might serve as a starting point for an analysis of library decision making. They are restated below as hypotheses.

1. There are no community values which are usually agreed upon, but only the values of specific groups and individuals, many of which are conflicting.

2. The many conflicting values cannot be compared or weighted: for example, it is impossible to compare or weight the value of individual dignity against the loss of rare books.

3. The environment of library policy makers, particularly the power and influence system, renders it impossible for them to see or accurately weight many community values, particularly those values which have no active or powerful proponents.

4. Library policy makers are not motivated to make decisions on the basis of community goals, but instead try to maximize their own rewards-power, status, money, etc.

5. Library policy makers are not motivated to maximize net goal achievement, but merely to satisfy demands for progress; they do not search until they find "the one best way" but halt their search when they find an alternative which "will work."

6. Large investments in existing programs and policies (e.g., catalog- ing systems, library buildings, and other "sunk costs") prevent policy makers from reconsidering alternatives foreclosed by previous decisions.

7. There are innumerable barriers to collecting all of the information required to know all possible policy alternatives and the consequences of each alternative, including the cost of information gathering, the availability of the information, and the time involved in its collection.

8. Neither the predictive capacities of the social and behavioral sciences nor the predictive capacities of the physical and biological sciiences are sufficiently advanced to enable policy makers to understand the full range of consequences of each library policy alternative.

9. Library policy makers, even with the most advanced computerized analytical techniques, do not have sufficient intelligence to calculate accurately cost-benefit ratios when a large number of diverse political, social, economic, and cultural values are at stake.

10. Library policy makers have personal needs, inhibitions, and inadequacies which prevent them from performing in a highly rational manner.

11. Uncertainty about the consequences of various policy alternatives compels policy makers to stick as closely as possible to previous policies to reduce the likelihood of disturbing, unanticipated consequences.

12. The segmentalized nature of policy making in large library bureaucracies makes it difficult to coordinate decision making so that the input of all of the various specialists is brought to bear at the point of decision. ${ }^{33}$ 
Testing these hypotheses requires an analysis of the values and personal goals of library decision makers, the power of competing interests in universities, the incentive structures surrounding library administrators, and the nature of information available to decision makers. Significant normative questions follow. Should library decision makers be more representative of those who use the libraries? Should the incentive structure for advancement in library administration be altered to better reflect user and potential user demand?

\section{LESSONS FOR LIBRARIANS}

Unfortunately, whereas economists can advocate that library decision makers try to maximize benefits at a given budget level, political scientists can offer no clear-cut decision rule as an alternative. This paper ends with questions that library decision makers should ask, but no simple answers of what actions to take if answers are found can be offered at this point. ${ }^{34}$ Future research is needed, although this obviously will not solve all the political problems of librarians.

Following the more complete Easton model, library decision makers should ask themselves:

1. What is the relevant library system? Have I excluded a key component that determines user behavior but has traditionally fallen outside my purview? Can I coordinate decisions between my area and the additional area?

2. What are the environmental constraints that appear to limit my discretion? Can they be altered?

3. What groups (and individuals) make demands? Are they represent- ative of the potential users of the library? What preferences do not become demands? Are new or revised mechanisms needed to encourage more demands?

4. What is the general climate of opinion with respect to the library, e.g., support for library? Has the climate provided me with so much latitude that demands remain unmet? What assumptions (of users or administrators) limit the consideration of alternative policies? Who benefits from these assumptions? Who does not benefit? Can the asumptions be changed?

5. Who plays a role in decisions about library allocations? To what extent are users or potential users involved? To what extent are those affected by decisions helping to make them?

6. Who benefits from (and pays for) the library? Does the budget show this? What services serve what groups? How well are they served?

7. What feedback is available to the decision maker to evaluate current allocations? What mechanisms for feedback exist? Are they successful in bringing evaluations of users to decision makers? Do nonusers have access and do they use feedback systems?

In brief, political systems analysis is analogous to economic systems analysis: it is a way of thinking.

Woodrow Wilson, asked whether he had much difficulty in accustoming himself to practical politics, stated that after his experience in university politics at Princeton everything else seemed simple. It is time that we all recognized the politics of libraries and acted accordingly.

\section{REFERENCES}

1. Jeffrey A. Raffel and Robert Shishko, Systematic Analysis of University Libraries:
An Application of Cost-Benefit Analysis to the M.I.T. Libraries (Cambridge, Mass.: 
M.I.T. Press, 1969). Our M.I.T. editor said goodbye to us with the comment, "I hope you get some reviews." When we replied, "You mean some good reviews," she responded, "No, just some reviews."

2. General references in the area of cost-benefit analysis include Charles I. Hitch and Roland N. McKean, The Economics of Defense in the Nuclear Age (Cambridge, Mass.: Harvard Univ. Pr., 1960); and David Novick, ed., Program Budgeting: Program Analysis and the Federal Budget (Cambridge, Mass.: Harvard Univ. Pr., 1965). References on the "economics of information" can be found in Harold Anker Olsen, The Economics of Information: Bibliography and Commentary on the Literature (Washington, D.C.: ERIC Clearinghouse on Library and Information Sciences, 1971). (ED 044545 ).

3. Mancur Olson, "Economics, Sociology, and the Best of All Possible Worlds," The Public Interest, no. 12 (Summer 1968), p.96118.

4. Olsen, Economics of Information, p.1.

5. Jeffrey A. Raffel and Robert Shishko, "CostBenefit Analysis for Library Administrators," paper presented to Massachusetts Chapter of the Special Libraries Association on March 11, 1969, in Boston, Massachusetts.

6. Melvin R. Levin and Alan Shank refer to cost-benefit analysis "as a measurement technique in which the total costs of a given project or program are compared with the probable total benefit. . . . The result is a numerical ratio. ..." Cost-effectiveness is viewed as a variation of cost-benefit analysis where the output is expressed in "raw form without conversion to dollars." See Levin and Shank, eds., Educational Investment in an Urban Society: Costs, Benefits, and Public Policy (New York: Teachers College Press, 1970), p.1-2.

Using this distinction, I refer primarily to cost-effectiveness analysis in its application to libraries and cost-benefit analysis as the general approach.

7. Raffel and Shishko, "Cost-Benefit Analysis," p.2.

8. Late in the M.I.T. analysis it became evident that an advertising objective of the library was also significant; that is, librarians wanted to encourage those in the university community to increase their use of the library. Thus attempts were made to entice book use by lavishly furnishing lounges in the libraries. This goal was rarely acknowledged.

9. In the M.I.T. study we tried to resolve this problem by asking potential users to judge benefits themselves.

10. Raffel and Shishko, Systematic Analysis of University Libraries, p.50-55.

11. Ibid., p.46-67.

12. Terry N. Clark, in an unpublished paper titled "Please Cut the Budget Pie" (research paper \#37 of the Comparative Study of Community Decision-Making, Summer [1972]), develops a further rationale and somewhat different methodology to measure citizen preferences for various public policies.

13. Raffel and Shishko, Systematic Analysis of University Libraries, p.65.

14. There is a literature in economics (welfare economics and public choice economics) on this subject. The proposed solutions include: (1) maximizing total utility across individuals-but this requires the interpersonal comparison of utility and the measure of utility, both problematic procedures; (2) transforming costs and benefits into dollars and maximizing the net figure-but the full transformation is usually impossible and questions like those raised in the first method still arise; and (3) only taking those actions that make no one worse off and at least one person better off-but this case arises infrequently in the era of declining or steady budgets.

I am indebted to the critiques of costbenefit analysis by Aaron Wildavsky. See his "The Political Economy of Efficiency: Cost-Benefit Analysis, Systems Analysis and Program Budgeting," Public Administration Review 26:292-310 (Dec. 1966); and "Rescuing Policy Analysis from PPBS," in Public Administration Review: PPBS Reexamined 29:189-202 (March/April 1969).

15. David Easton, A Systems Analysis of Political Life (New York: Wiley, 1965).

16. Alan Rosenthal, ed., Governing Education: A Reader on Politics, Power, and Public School Policy (Garden City, N.Y.: Anchor Books, 1969), p.viii-ix.

17. See Frederick Wirt and Michael Kirst, The Political Web of American Schools (Boston: Little, 1972), for one volume applying Easton's framework to the politics of education.

18. See Sanford A. Lakoff and Daniel Rich, eds., Private Government: Introductory Readings (Glenview, Ill.: Scott, Foresman, 1973), for an excellent discussion of the rationale for studying the politics of private government and case studies, including the politics of university governance.

19. Ibid., p.3.

20. See Sanford Lakoff, "Private Government 
in the Managed Society," in Lakoff and Rich, eds., Private Government, p.218-42.

21. Lakoff and Rich, Private Government, preface.

22. Harold Lasswell, Politics: Who Gets What, When, and How (Glencoe, Ill.: Free Press, 1958).

23. Thomas Dye recently described several models used in analyzing public policy: (a) elite-mass model, (b) group model, (c) incremental model, (d) institutional model, (e) systems model, and (f) rational model. See Thomas R. Dye, Understanding Public Policy (Englewood Cliffs, N.J.: Prentice-Hall, 1972).

24. Dye, Understanding Public Policy, p.1819. Dye's conceptualization is based upon David Easton, "An Approach to the Analysis of Political Systems," World Politics 9:383-400 (1957); and Easton, A Framework for Political Analysis (Englewood Cliffs, N.J.: Prentice-Hall, 1965).

25 . In the preference survey at the $\$ 0$ budget level, although differences were small, faculty were somewhat more satisfied as measured by the percentage desiring changes from current allocations.

26. The reader should note that this paper is not an indictment of M.I.T. in particular, although there is evidence that the libraries are governed in the same way as are other elements of the university (e.g., health services, graduate school).

27. These arguments relate to a larger battle among elitists, pluralists, neoelitists, and so on. See Dye, Understanding Public Policy.

28. Peter Bachrach and Morton S. Baratz, Power and Poverty: Theory and Practice (New York: Oxford Univ. Pr., 1970), p.9.

29. John E. Keller, "Program Budgeting and Cost Benefit Analysis in Libraries," College \& Research Libraries 30:160 (March 1969).

30 . It should be noted that many university libraries charge fees for use, for reproduction and for organizational users. My own opinion is that fees for the former are far too high and the latter far too low. In any event, both require further political analysis.

31. Albert Hirschman, Exit, Voice, and Loyal- ty (Cambridge, Mass.: Harvard Univ. Pr., 1970).

32. Lakoff, "Private Government in the Managed Society," p.229.

33. Dye, Understanding Public Policy.

34. Note that analogous questions arise about public libraries. Political scientist Edward Banfield is one of a few people to raise explicit political questions about public libraries. Banfield begins his discussion of urban libraries with the question of their purpose. "It [the urban library] is trying to do some things that it probably cannot do, and it is doing others that it should not do."

In Easton's terms the question expands: (a) What is the relevant system? Educational institutions? Information institutions? (b) What are the outputs of the library? What groups does it serve? How well does it serve them? (c) Why does the library try to serve these groups? What demands does it try to meet? What preferences never become demands? What tasks might it accomplish that are not now viewed as appropriate?

Banfield argues that libraries should serve "serious," not "light," readers; the latter group could be served by rental and paperback libraries. But most serious readers can pay for the services they receive. Should the general public then pay for a subgroup to receive the services?

Perhaps what Banfield is trying to communicate is that although the cost of library services may serve as the focal point for library decision making and public concern (e.g., closing and reduction in services of public libraries), the basic problem of public libraries is not an economic problem. Rather, we have not examined library priorities and reallocated library resources to meet changing political circumstances. Only a political analysis will indicate why this is so and what changes should be made.

See Edward C. Banfield, "Some Alternatives for the Public Library," in Ralph W. Conant, ed., The Public Library and the City (Cambridge, Mass.: M.I.T. Press, 1965), p.102-13. 